\title{
Comprehensive optimization of district systems water supply and sewerage taking into account different ways of transporting water and effluents
}

\author{
Viktor R. Chupin ${ }^{l}$, and Mariya V. Moroz ${ }^{l}$ \\ ${ }^{1}$ Irkutsk National Research Technical University, 664074, Lermontov str. 83, Irkutsk, Russia
}

\begin{abstract}
The issues of the choice of routes, the composition of structures, and especially the methods of transporting water and wastewater, the justification of the locations of water intakes, treatment facilities are relevant and require special attention and technical and economic analysis and justification of design solutions. The paper investigates the areas of application of various types of transport of water and wastewater, depending on the volume, range, cost of electricity and fuel, vehicle designs and pipelines. Taking into account the obtained ranges of application of various types of transport, models and methods for optimizing the structure and parameters of water supply and sewerage systems have been improved.
\end{abstract}

\section{Introduction}

Currently, road transport for the delivery of drinking water and disposal of wastewater has become widespread for sparsely populated areas. However, there are no strict justifications for the applicability of this type of transport. Therefore, the issues of choosing the type of transportation of drinking water, source and treated effluents are relevant and require appropriate research. The expediency of the appointment of a particular type of transport depends on many factors and a specific situation. This raises the question of at what productivity and demand for water supply and sewerage it is economically profitable to use this or that mode of transport and at what distance. Such dependencies can be obtained on the basis of processing the cost indicators of the corresponding modes of transport.

\section{Methods}

The generally accepted criterion for optimization and comparison of options is the reduced (to one year) costs for the construction and operation of a hot water supply system, which are determined as follows [1]:

$$
\mathrm{C}_{\mathrm{red}}=\mathrm{K} \cdot \mathrm{E}+\mathrm{O}_{\mathrm{c}},
$$

where $\mathrm{C}_{\text {red }}$ is reduced costs, thousand rubles/year; $\mathrm{K}$ is capital investment in the network, thousand rubles; $\mathrm{E}$ is the coefficient of efficiency of capital investments, which in a market economy is identified with bank interest; $\mathrm{O}_{\mathrm{c}}$ is annual operating costs (thousand rubles/year) calculated based on recommendations for the regulation of labor of workers in the water 
supply and sewerage sector (Order of the State Construction Committee of the Russian Federation of June 15, 2020 No. 316/pr) and are determined according to [2,3,4]. The most effective optimization criterion is the life cycle costs [3], which, taking into account the system life cycle ( $T$, in years), can be obtained by transforming (1):

$$
\mathrm{LCC}=\mathrm{K} \cdot \mathrm{T} / \mathrm{t}_{\mathrm{p}}+\mathrm{T} \cdot\left(\mathrm{O}_{\mathrm{c}}\right)
$$

where $t_{p}$ is the amortization life of the system. For example, with a life cycle of 50 years and a service life of a car of 8 years, it will have to be updated 6.26 times. The same applies to other elements of a complex system.

\section{Pipeline systems}

To concretize the one-time (capital) costs, we will use the information given in the consolidated standards for construction prices (NCS 81-02-14-2020). For external water supply networks $1 \mathrm{~km}$ long consisting of polyethylene pipes, when developing dry soil to a depth of $3 \mathrm{~m}$ (which is typical for the Irkutsk Region), it is not difficult to obtain the following dependence of capital investments on the diameter of the pipeline:

$$
\mathrm{K}=\left(50246 \cdot d^{2}-10277 \cdot d+5363.6\right) \cdot L
$$

$\mathrm{K}$ - investment, in thousand rubles, $\mathrm{d}$ - diameter, in $\mathrm{m}$.

$$
d=\sqrt{\frac{4 x}{\pi v}}
$$

where $\mathrm{v}$ is the velocity in $\mathrm{m} / \mathrm{s}, \mathrm{x}$ is the water flow rate in the pipeline section of the network, in $\mathrm{m}^{3} / \mathrm{s}$. Taking into account (4), formula (3) will take the following form:

$$
K=\left(63812.42 \cdot x \cdot v^{-1}-11602.73 \cdot x^{0.5} \cdot v^{-0.5}+5363.6\right) \cdot L
$$

Operating costs include the annual costs of electricity $\mathrm{C}_{\mathrm{el}}$ (thousand rubles/year):

$$
C_{e l}=108 \cdot z_{e l} \cdot H \cdot x,
$$

Where $\mathrm{z}_{\mathrm{el}}$ is the cost of $1 \mathrm{kWh}, \mathrm{H}$ is the head developed by the pumping station, in $\mathrm{mm} \mathrm{H} 2 \mathrm{O}$

The calculation of electricity costs requires separate consideration. In the theory of hydraulic circuits [5], the energy conservation law for an arbitrary hydraulic circuit is formulated as follows: "All the energy brought in, minus the energy for pouring out water, is spent on overcoming friction forces":

$$
\sum_{j=1}^{J_{1}} Q_{j} \cdot H_{j}-\sum_{j=1}^{J_{2}} Q_{j} \cdot P_{j}=\sum_{i=1}^{n} h_{i} \cdot x_{i}
$$

where $J_{1}$ is a set of nodes of pumping stations, $J_{2}$ is a set of nodes for water consumption, $\mathrm{H}_{\mathrm{j}}$ is piezometric heads of pumping stations, $\mathrm{P}_{\mathrm{j}}$ is piezometric heads of water at consumers, in meters, hi is head losses along sections of the water supply network, $Q_{j}$ is water consumption at consumer $\mathrm{j}, \mathrm{m}^{3} / \mathrm{s}$.

Therefore, the annual electricity costs for the water supply system can be represented as the sum of electricity costs for each section of the network:

$$
C_{\text {элк }}=108 \cdot z_{\text {элк }} \cdot \ni_{i}, \ni_{i}=h_{i} \cdot x
$$

To simplify the presentation and calculation of head losses along the length of the pipeline, we use the formula of F.A. Shevelev for plastic pipes [6] and given (4) it will look like this:

$$
h_{i} \cdot x_{i}=0.000649 \cdot L_{i} \cdot x_{i}^{0.387} \cdot v_{i}^{2.387} \text {. }
$$


It is not difficult to reduce the costs of electricity to a section of the pipeline network 1 $\mathrm{km}$ long and express them as a function of the flow rate and velocity of water movement:

$$
\mathrm{C}_{e l}=108 \cdot z_{e l} \cdot\left(0.000649 \cdot L_{i} \cdot 1000 \cdot x_{i}^{0.387} \cdot v_{i}^{2.387}+p_{i} \cdot x_{i}\right),
$$

$\mathrm{L}$ is length in $\mathrm{km}, \mathrm{P}_{\mathrm{j}}$ is piezometric heads of water at consumers (for example, $10 \mathrm{~mm} \mathrm{H} 2 \mathrm{O}$ ).

The costs of operating water supply systems according to [7,8] are expressed as deductions from capital investments:

At constant operating costs, the life cycle costs for water systems can be recorded as follows:

$$
L C C=\mathrm{K} \frac{\mathrm{T}}{t_{p}}+T \cdot\left(0.11 \cdot K+C_{e l}\right)
$$

As a result, we obtained the life cycle costs as a function of the flow rate and velocity of the transported water, the length of the pipeline and the specific electricity costs. SP 31.13330 .2012 and a number of guidelines recommend the velocity of water movement in the range of $1.5-3 \mathrm{~m} / \mathrm{s}$. However, in each case, the economic velocity can be determined by calculation. For this, it is necessary to take the partial derivative of the reduced costs and life cycle costs in terms of velocity and equate to zero. Next, solve the resulting equation for the velocity.

To select the economic velocities, we will carry out numerical experiments in relation to life cycle costs, varying unit values of electricity costs and the length of pipelines. The unit cost of electricity will vary from the lowest for the Irkutsk Region - 1.11, to the maximum for Chukotka - 8.5 rubles per kWh. The results of numerical experiments are presented in Tables 1 and 2, from which it follows that the tariff for electricity and the volumes of pumped water and wastewater have a significant effect on the optimal values of speeds. The length of the networks practically does not affect the speed of water movement. Life Cycle Cost Criterion Reduces Optimal Speed by $25 \%$.

Table 1. Estimation of the economic velocities of water movement along pressure pipelines

\begin{tabular}{|c|c|c|c|c|c|c|c|}
\hline \multirow{2}{*}{$\begin{array}{c}\text { Electricity } \\
\text { cost, rubles } \\
\text { per kWh, } Z_{\text {el }}\end{array}$} & \multicolumn{7}{|c|}{ Economic velocity of water movement (m/s) for a route length of $1 \mathrm{~km}$} \\
\cline { 2 - 8 } & $0,1 \mathrm{~m}^{3} / \mathrm{s}$ & $0,5 \mathrm{~m}^{3} / \mathrm{s}$ & $1 \mathrm{~m}^{3} / \mathrm{s}$ & $1,5 \mathrm{~m}^{3} / \mathrm{s}$ & $2 \mathrm{~m}^{3} / \mathrm{s}$ & $2,5 \mathrm{~m}^{3} / \mathrm{s}$ & $3 \mathrm{~m}^{3} / \mathrm{s}$ \\
\hline 1 & 1,8 & 2,6 & 3 & 3,3 & 3,5 & 3,6 & 3,7 \\
\hline 2 & 1,5 & 2,1 & 2,5 & 2,7 & 2,8 & 3 & 3,1 \\
\hline 3 & 1,3 & 1,9 & 2,2 & 2,4 & 2,5 & 2,6 & 2,7 \\
\hline 4 & 1,2 & 1,8 & 2 & 2,2 & 2,3 & 2,4 & 2,5 \\
\hline 5 & 1,2 & 1,6 & 1,9 & 2 & 2,2 & 2,3 & 2,3 \\
\hline 6 & 1,1 & 1,6 & 1,8 & 1,9 & 2,1 & 2,1 & 2,2 \\
\hline 7 & 1,1 & 1,5 & 1,7 & 1,9 & 2 & 2,1 & 2,1 \\
\hline 8 & 1 & 1,4 & 1,7 & 1,8 & 1,9 & 2 & 2 \\
\hline 9 & 1 & 1,4 & 1,6 & 1,7 & 1,8 & 1,9 & 2 \\
\hline 10 & 1 & 1,3 & 1,5 & 1,7 & 1,8 & 1,8 & 1,9 \\
\hline
\end{tabular}

Table 2. Evaluation of the optimal flow rates of wastewater through pressure pipelines

\begin{tabular}{|c|c|c|c|c|c|c|c|}
\hline \multirow{2}{*}{$\begin{array}{c}\text { Electricity } \\
\text { cost, }\end{array}$} & \multicolumn{6}{|c|}{ Economic velocity of sewage movement (m/s) for a route length of $1 \mathrm{~km}$} \\
\cline { 2 - 7 } & \multicolumn{7}{|c|}{ For life cycle costs (T=50 years) } \\
\cline { 2 - 7 } & $0,1 \mathrm{~m}^{3} / \mathrm{s}$ & $0,5 \mathrm{~m}^{3} / \mathrm{s}$ & $1 \mathrm{~m}^{3} / \mathrm{s}$ & $1,5 \mathrm{~m}^{3} / \mathrm{s}$ & $2 \mathrm{~m}^{3} / \mathrm{s}$ & $2,5 \mathrm{~m}^{3} / \mathrm{s}$ & $3 \mathrm{~m}^{3} / \mathrm{s}$ \\
\hline
\end{tabular}




\begin{tabular}{|c|c|c|c|c|c|c|c|}
\hline $\begin{array}{c}\text { rubles per } \\
\mathrm{kWh}, \mathrm{Z}_{\mathrm{el}}\end{array}$ & 1,5 & 2,1 & 2,4 & 2,6 & 2,8 & 2,9 & 3 \\
\hline 1 & 1,2 & 1,7 & 2 & 2,3 & 2,3 & 2,4 & 2,5 \\
\hline 2 & 1,1 & 1,5 & 1,8 & 1,9 & 2 & 2,1 & 2,2 \\
\hline 3 & 1 & 1,4 & 1,6 & 1,8 & 1,9 & 1,9 & 2 \\
\hline 4 & 1 & 1,3 & 1,5 & 1,6 & 1,7 & 1,8 & 1,9 \\
\hline 5 & 0,9 & 1,3 & 1,4 & 1,6 & 1,7 & 1,7 & 1,8 \\
\hline 6 & 0,9 & 1,2 & 1,4 & 1,5 & 1,6 & 1,6 & 1,7 \\
\hline 7 & 0,8 & 1,2 & 1,3 & 1,4 & 1,5 & 1,6 & 1,6 \\
\hline 8 & 0,8 & 1,1 & 1,3 & 1,4 & 1,5 & 1,5 & 1,6 \\
\hline 9 & 0,8 & 1,1 & 1,2 & 1,3 & 1,4 & 1,5 & 1,5 \\
\hline 10 & & & & & & & \\
\hline
\end{tabular}

Calculations for $1 \mathrm{~km}, 10 \mathrm{~km}, 50 \mathrm{~km}, 100 \mathrm{~km}$ showed that the distance does not affect the economic velocity of fluid movement. The velocity increases with increasing volumes of transported water. Substituting (10) into expressions (5) and (8) for the cost of electricity in 1 ruble per $\mathrm{kWh}$, we obtain capital investments and electricity consumption as a function of water consumption:

$$
\begin{gathered}
K=\left(21377.2 \cdot x^{0.7853}-6716.82 \cdot x^{0.393}+5363.6\right) \cdot L \\
\mathrm{C}_{e l}=108 \cdot z_{e l} \cdot\left(8.82173 \cdot L_{i} \cdot x^{0.8995}+p_{i} \cdot x_{i}\right) .
\end{gathered}
$$

Similar dependencies were obtained for pressure sewerage

$$
\begin{gathered}
K=\left(12639.6 \cdot x^{0.7956}-3282.658 \cdot x^{0.3978}+5363.6\right) \cdot L \\
\mathrm{C}_{e l}=108 \cdot z_{e l} \cdot\left(5.2797 \cdot L_{i} \cdot x^{0.8749}+p_{i} \cdot x_{i}\right)
\end{gathered}
$$

\section{Road transport}

On the basis of $[9,10]$, the work carried out similar studies and determined the dependences of the life cycle costs of road transport for the transportation of drinking and waste water at various distances.

\section{Determining optimal areas for the use of various types of water and waste transport}

For this purpose, based on the obtained dependences (9), (11), (12), (15), for different distances, we will construct dependence diagrams of the life cycle costs for pipeline and road transport with tank capacities of $20 \mathrm{~m} 3$. These diagrams are shown in Figures 1 and 2. 


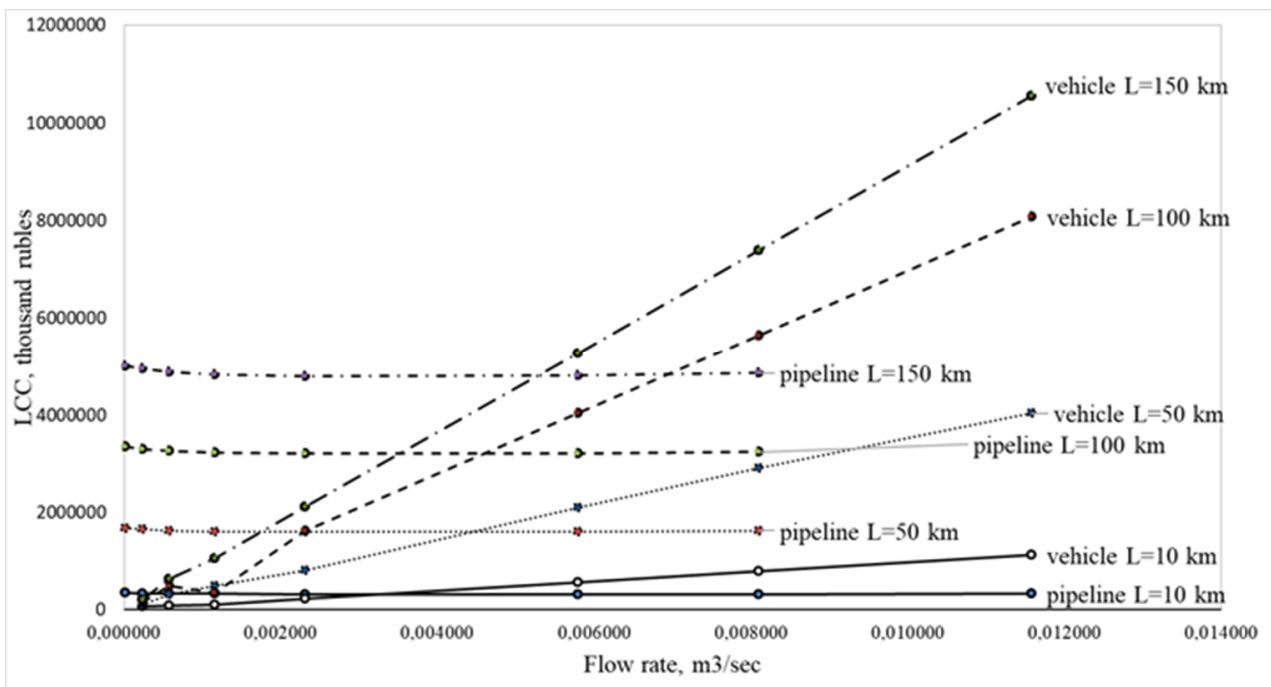

Fig. 1. Determining the area of use of various types of water transport

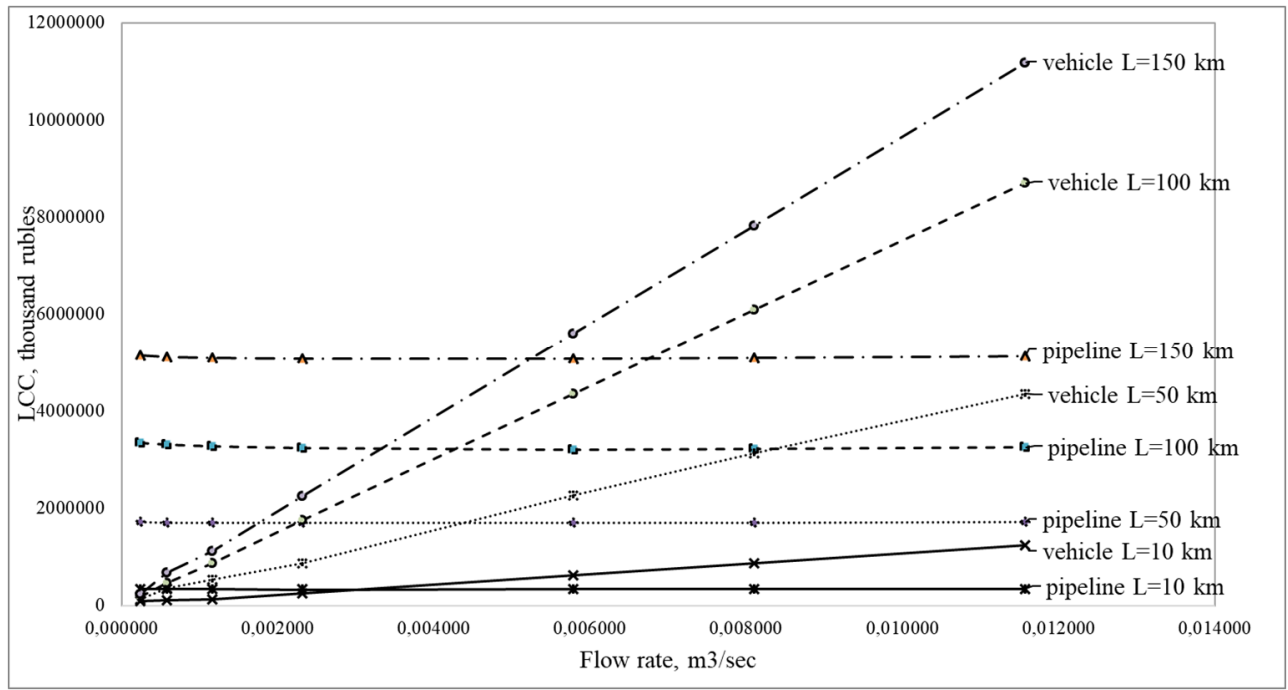

Fig. 2. Determining the area of use of various types of wastewater transport

As you can see from the figure, the trend lines for the life cycle costs for pipelines and road transport have intersection points. What gives us the area of effective use of road transport for the transportation of water and wastewater. When calculating, the cost of electricity for the Irkutsk region $(1.11$ rubles $/ \mathrm{kWh})$ was taken, which is significantly lower than in many other regions, and therefore for other regions the field of application of road transport can significantly expand.

\section{Conclusion and Discussion}

Thus, the obtained dependences make it possible to determine the economically optimal areas of application of road transport of water and wastewater. Taking into account the research conducted, all approaches to optimizing water supply and sewerage systems have been developed [11-20]. 


\section{References}

1. Economics of water supply and sewerage: a methodological guide for studying the discipline and for independent work of full-time students (Vologda, VolSU, 2013)

2. E.S. Gogina, A.D., Gurinovich, Water Supply and Sanitary Technique, 9, 36 (2016)

3. V.I. Bazhenov, E.I. Pupyrev, G.A. Samburskiy, S.E. Berezin, Water Supply and Sanitary Technique, 2, 10 (2018)

4. Drawing up the technical and economic part of the off-site water supply and sewerage projects (Reference manual to SNiP) (Moscow, Stroyizdat, 1991)

5. A.P. Merenkov, V. Ya. Hasilev, Hydraulic circuit theory (Moscow, Science, 1985)

6. N.N. Abramov, M.M. Pospelova, M.A. Somov and etc., Calculation of water supply networks (Moscow, Stroyizdat, 1983)

7. Z.G. Lyubanskaya, P.P. Osipov, Economics of water supply and sewerage systems. Calculation of operating costs in water supply and sewerage systems: guidelines and tasks for performing test work for students of the specialty 270112.65 "Water supply and sewerage" and bachelors in the direction of "Construction" (Khabarovsk, Publishing house of the Pacific State University, 2012)

8. Manual on water supply and sewerage in urban and rural areas (to SNiP 2.07.01-89) (M: Stroyizdat, 1992)

9. I.S. Turevsky, Industry economics. Automobile transport (Moscow, PH «FORUM»: INFRA-M, 2011)

10. A.A. Tozik, Road Transport Economics (Minsk, UE Technoprint», 2005)

11. R.V. Chupin, N.M. Pham, Water Supply and Sanitary Technique, 1, 30 (2019)

12. R.V. Chupin, Water Supply and Sanitary Technique, 2, 67 (2018)

13. R.V. Chupin, E.S. Melekhov, Development of theory and practice of modeling and optimization of water supply and sewerage systems (Irkutsk, Publishing house of ISTU, 2011)

14. R.V. Chupin, Optimization of developing drainage systems (Irkutsk, Publishing House of Irkutsk State Technical University, 2015)

15. H. Taha, Introduction to Operations Research (Moscow, World, 1985)

16. L.R. Ford, D.R. Fulkerson, Streams in networks (Moscow, World, 1963)

17. T. Hu, Integer programming and network streams (Moscow, World, 1974)

18. R.V. Chupin, N. M. Pham, V.R. Chupin, IOP Conf. Series: Materials Science and Engineering, 667 (2019)

19. R.V. Chupin, N. M. Pham, V.R. Chupin, IOP Conf. Series: Materials Science and Engineering, 667 (2019)

20. E.S. Melekhov, V.R. Chupin, R.V. Chupin, Certificate of state registration of a computer program №2016615463 TRACE-VR (25 May 2016) 